\title{
Defect characterization of KTP single crystals
}

\author{
G DHANARAJ, T SHRIPATHI* and H L BHAT \\ Department of Physics, Indian Institute of Science, Bangalore 560012, India \\ *Pormanent address: Inter-University Consurtium lor DAE Facilities, Unjuersity Campus, \\ Khandwa Road, Indore 452 or 1 , India
}

Abstract. Potassium titanyt phosphate (KTP) is a relatively rew nunlinear optical material with excellent combination of plyysical properties. This paper presents the combined etching and $X$-cay topographic studies carried out on KTP erystals with a wew 10 characterizing their Selects. KTP erystals temployed in this investigation were grown from Iux. Optical microscopic study of habit faces revealed growth layers and growtl hillocks on [100) and $\{01$ I Bices respectively. Etching of $\{011$, habit laces proved that growrth hillocks corresponded :o the emergence point of dislocation out crops on these faces. The stitability of the new ctchunt to reveal dislocition was conlirmed by etehing the matched pairs obtained by deivirg. The defects present in the crystal were also studied by $X$-ray topography. The defect conliguration in these crystals is characteristic of crystals grown from solution. The dislocations ate prodominantly linear with their origin either at the nuelcation centre or Intilısions. In general, grown crystals were found to have low dislocation densily and often large volumes of crystals free from dislocation could be obtained.

Keywords. Flux growth; growh hillocks; eching: X-ray topography; dislocations.

\section{Introduction}

Potassium titanyl phosphate, $\mathrm{KTiOPO}_{4}$, commonly known as KTP, is one of the tcchnologically important ferroelectric crystals with Curie temperalure $934^{\circ} \mathrm{C}$ (Bicrlein and Vanherzecte 1989; Yanovskii and Voronkova 1986). Its crystal structure belongs to orhorhombic space group Pna2 ${ }_{1}$ (Tordjman et al 1974). It has excellent combination of properties such as high nonlincar optical coefficients, high damage threshold, thermally insensitive phase matching and good chemical and mechanical properties that makes it useful for second harmonic generation of the $1.06 \mu \mathrm{m} \mathrm{Nd:YAG}$ laser (Zumsteg et al 1976). Its large electro-optic coefficients and low diclcetric constant make it more attractive for various electro-optic applications especially in wa ve guides. Even though its physical properties have been extensively studied and applied in various device fabrication for the past several years, there does not seem to be much systematic work carried out on defect characterization of KTP crystals. Cai and Yang (1986) reported the etch pit micrographs without giving any details. Bolt et al $(1991 \mathrm{a}, \mathrm{b})$ carried out X-ray topographic studies as well as etching studies. However, the latter were restricted to only habit faces and not on cleaved plates. In this paper we present onc results on the assessment of the quality of the grown crystals employing both chemical etching and $X$-ray topographic techniques. In particular, etching was carried out both on habit and cleaved faces. Our optical microscopic study has also given some insight to the growth mechanism of these crystals. 


\section{Experimental procedure}

The crystals employed in this investigation were grown from potassium phosphate Jlux $\left(\mathrm{K}_{6} \mathrm{P}_{4} \mathrm{O}_{13}\right)$ by slow cooling method. The appropriate amounts of ingredients i.e. $\mathrm{KH}_{2} \mathrm{PO}_{4}, \mathrm{~K}_{2} \mathrm{HPO}_{4}$ and $\mathrm{TiO}_{2}$ were taken in a platinum crucible and heated to $1050^{\circ} \mathrm{C}$ for homogenization. After two days, the temperature was brought down to $975^{\circ} \mathrm{C}$ after which the charge was cooled down to $650^{\circ} \mathrm{C}$ at controlled cooling rates. The cooling rate ranged from $2^{\circ} \mathrm{C} / \mathrm{h}$ to $7^{\circ} \mathrm{C} /$ day. Figure 1 shows typical KTP crystals grown in our laboratory.

Optical microscopy of the grown crystals was carried out employing a polarizing microscope (Leilz Orthoplan). Whenever necessary the reflectivity of the faces under examination was enhanced by depositing a thin layer of silver on the surface by vacuum evaporation. The etching experiment was carried out in a well-protected constant temperature batl. The etchant, a mixture of $\mathrm{HCl}$ and $\mathrm{HF}$ in the ratio 2:1 was taken in polyethylene container. Etching was done at $100^{\circ} \mathrm{C}$ for $45-120 \mathrm{~min}$. Crystals with habit faces as well as cleaved plates were used in this study. The etched laces were cleaned in distilled water and dried carelully without any damage to the surface and were then studied under optical microscope.

For X-ray topographic work, (100) plates were prepared by cutting the grown KTP crystals using a diamond saw. The crystal plates were thinned down to $0.75 \mathrm{~mm}$ by lapping using $0.5 \mu$ alumina abrasive powder. Mechanical strain present on the surface due to lapping of the crystal was removed by dissolving the surface in HF. X-ray topographs were recorded on Agfa Dentus M2 film with $\mathrm{MoK} \alpha$ radiation using Lang method. A Rigaku micro focus X-ray generator was used $\left(\mu=3.2 \mathrm{~mm}^{-1}\right.$ for $\left.0.709 \AA\right)$. (040) refection was selected because of its high intensity.

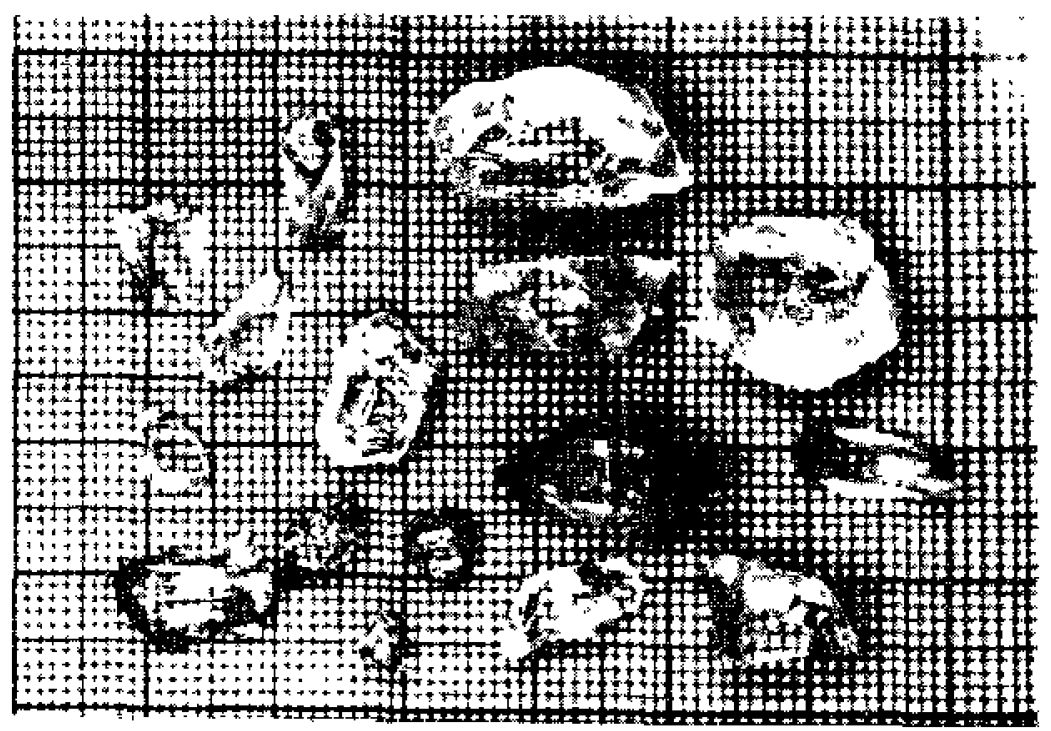

Figure 1. Typical KTP crystals grown from flux (mm scale). 


\section{Results and discussions}

\subsection{Surface structure}

Although the phosphate flux has its own advantage like the ability to give high purity crystal, the viscosity of this flux is high when compared to tungstate flux (Ballman et al 1986; Iliev et al 1990). Therefore, depending upon the temperature range and cooling rate, the surface structure of the KTP crystal and the cxtent of flux inclusion vary. When the cooling ratc is $1^{\prime \prime} \mathrm{C} / \mathrm{h}$ the resulting crystal surfaces exhibit coarse dendritic structure. Such dendritic structures are seen on both $\{100\}$ and $\{201\}$ habit faces. Figurc 2 shows a typical dendritic pattern on (201) face of a crystal grown under the above mentioned cooling rate. As the cooling rate decreases the surface dendritic patterns change from coarse to finer structure. Tho detailed study correlating the surlace structure to cooling rate was reported earlier (Dhanaraj et al 1990). Further, it is important to note that at high cooling rates flux inclusion in the bulk of the crystal is rather high. This flux inclusion deteriorates the optical quality of the crystal. As we decrease the cooling rate, the flux inclusion decreases and hence it is possible to grow crystals free from visible inclusions and dendritic structure on the habit faces.

When the crystal surfaces are lree from dendritic structure the underlying growth featuros become visible which reflect the true mechanisms operating in the growth of these crystals. The most prominent habit face (100) contains step pattern spreading smoothly over the entire face suggesting layer growth. On the other hand $\{011\}$ habit feces exhibit growth hillocks of various shapes and steepness. Figure 3a shows an atsymmetric hillock on $\{011\}$ habit face whereas figure 3 b shows a pyramid-like hillock on the same lace. As we shall see later these growth hillocks are an exterual

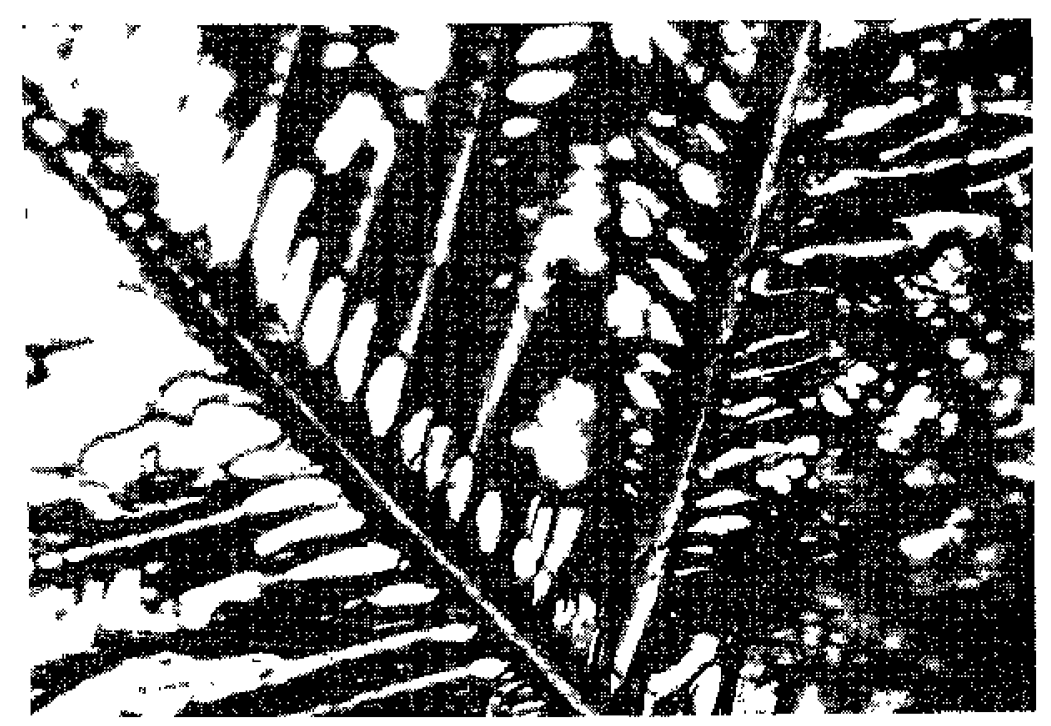

Figure 2. Dendritic pattern on (201) habit face $(\times 100)$. 


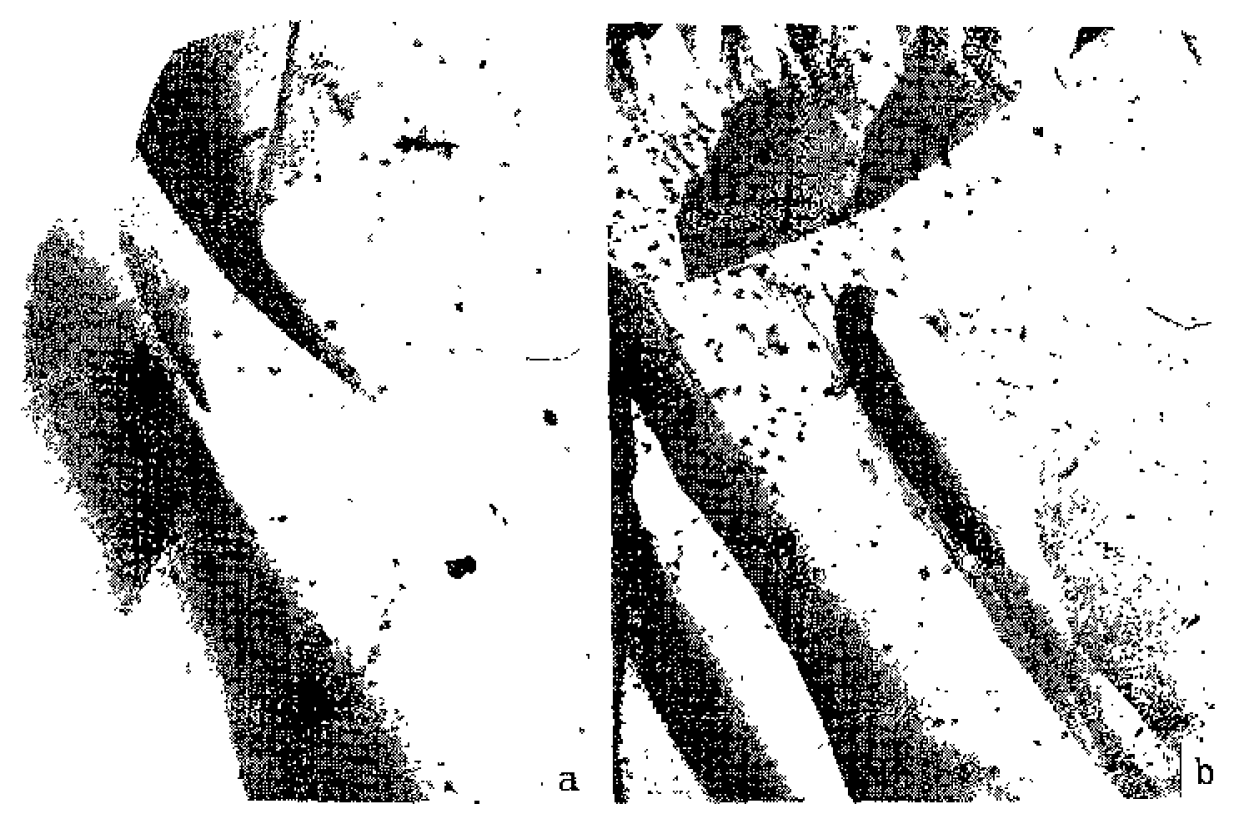

Figure 3. Hillocks on $\{01\}$ habit laces $(x 150\}$. a. Symmetric and b. asymmetric.

manifestation of the internal defect structure of the crystal. The probable reasons for different shapes of these hillacks wil] be discussed later.

\subsection{Ftching studies}

In order to study the dislocations present in the grown crystal, etching studies werc carried out. The crystals were etched in a $2: 1$ ratio $\mathrm{HCJ}$ and HF mixture at $100^{\circ} \mathrm{C}$ for 45-120 min. This etchant reveated dislocations on bolh the cleavage and habil faces. Figure 4 shows a typical etch pattern produced on (011) habit face. Etch pits could be produced on other habit faces as weil. The shape of the pits produced on the habit faces reflected the symmetry of these faces. The fact that this etchant was capable of revealing dislocations was first confirmed by etching the complimentary crystal surfaces obtained by cleaving. Figures $5 \mathrm{a}$ and $\mathrm{b}$ show etch patterns on onc such cleaved $\{100\}$ matched pair. Here one can clearly see a one-to-one correspondence between the number and the position of the etch pits proving that the pit was duc to dislocation emerging out of (100) plane. A magnified image of the dislocation pit is shown in ligure 5c. The tail-]ike nature of the dislocation etch pit is likely to be due to the facl that dislocation line is seen inclined to $[100]$ direction. Further, it should be noted here that the entire face conlained only one dislocation etch pit which in turn reflected high degree of perfection of the grown crystal. A few other shallow pits which do not show a onc-to-one correspondence may be due to clusters of point defects. As a matter of fact, on many occasions. one could not sce any pits in the entire cleaved plates when etched. Figure 6 shows a large area of cleaved (100) plate etched with the above etchant. It shows smooth dissolution pattern without any etch pit revealing that there is no growth or process-induced dislocation emerging 


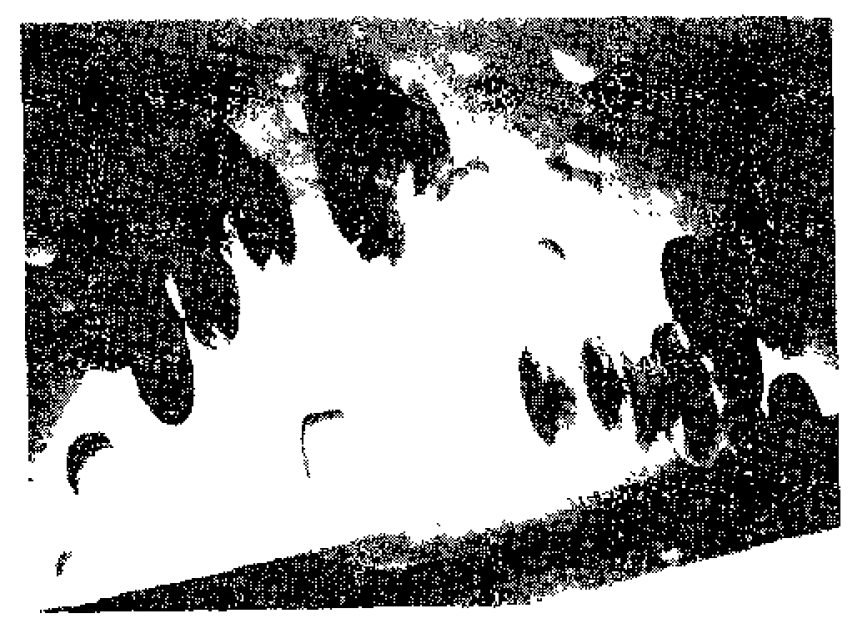

Figure 4. Typical with pittern on (011) habit lace $(\times 150)$.
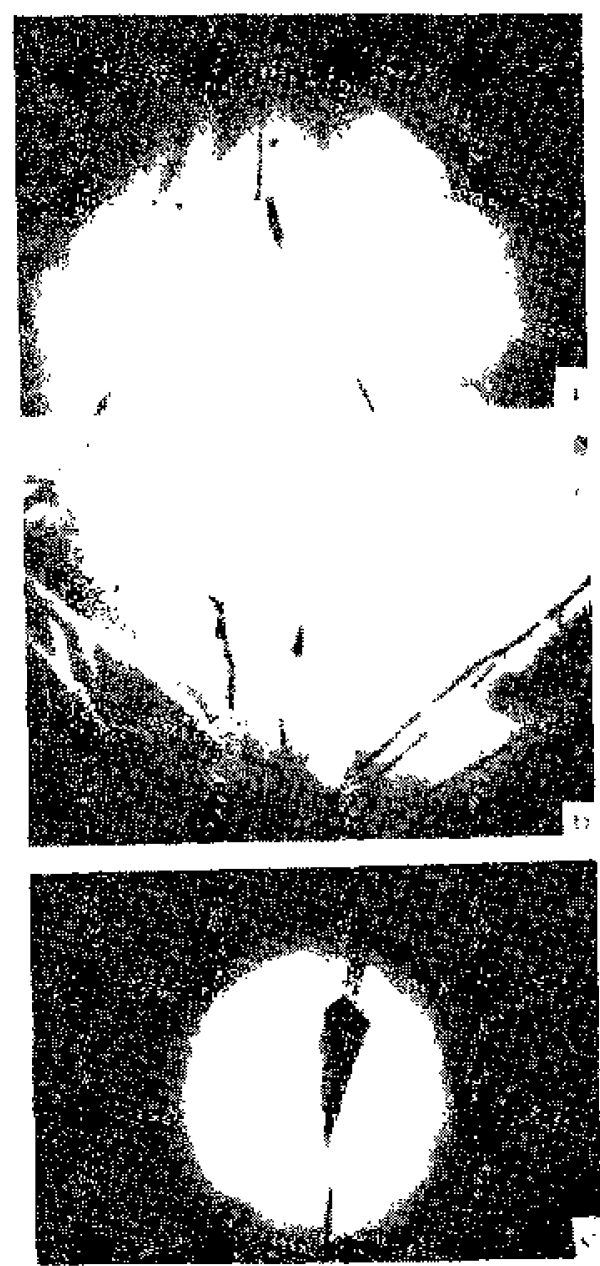

Figure 5. a-b. Etch patterns on cleaved $\{100\}$ matched pair $\left(\times 100 \times \frac{5.5}{7.5}\right)$. c. Magnified image of dislocotion etch pit shown in figure $59\left(\times 300 \times \frac{5.5}{7.5}\right)$. 


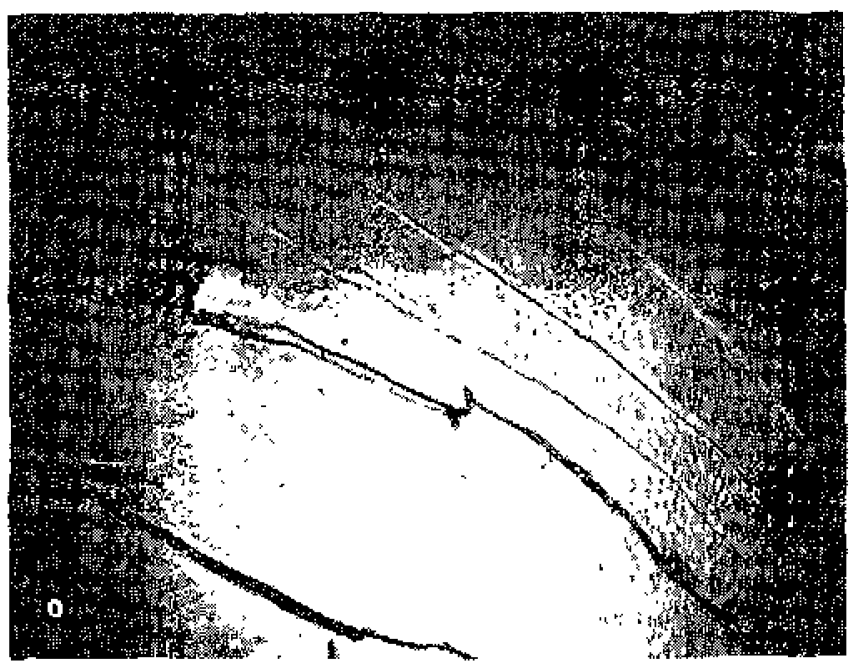

Figure 6. Etcli patiern on cleaced (100) plate showing smooth dissolution of the surjace without etch pits $(\times 150)$.

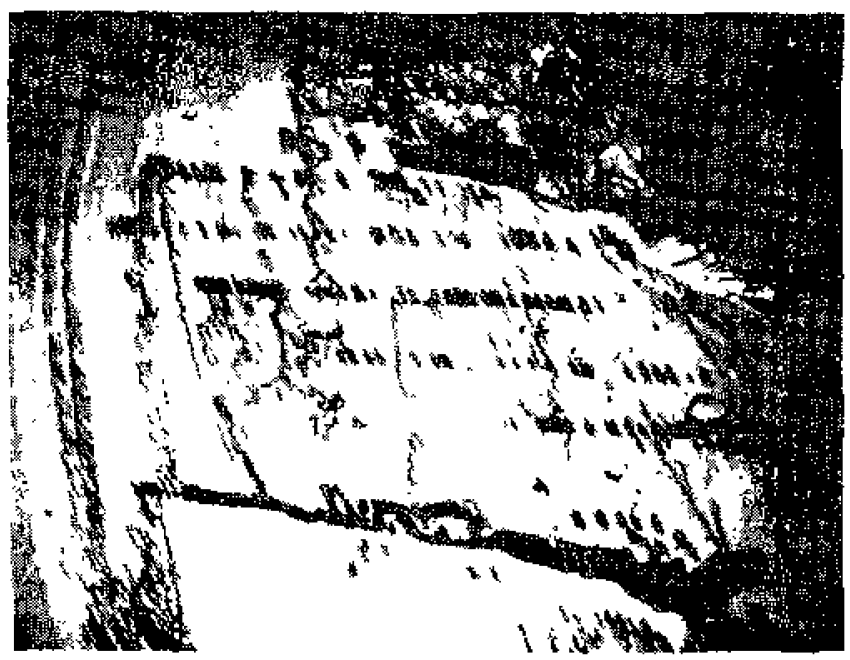

Figure 7. Etch pattern on cleaved (100) plate showing piling of dislocations $\{\times 150$.

out in (100) plane. In this etching study the dislocation densities were measured by counting the number of etch pits. The dislocation density ranged from a few dislocations per $\mathrm{cm}^{2}$ to $10^{3} / \mathrm{cm}^{2}$ depending upon the growth conditions.

Since KTP crystal is tmechanically quite stable (its hardness being 5.7 in Mohs scale), one cannot introduce mechanical dislocations easily into the crystal. Consequently normal handling procedures do nol adversely aflect the quality of the crystal. However, sometimes it is possible to see process-induced dislocations in cleaved crystals wher: cleaving is not perfect. Figure 7 shows one such cleaved plate in which distocation pits are piled up in rows, to attain minimum energy configuration. An identical etch pit pattern was observcd on the counter-part of the cleaved crystal. These are certainly dislocations introduced during cleavage process.

In order to understand the origin of the hillocks on $\{011\}$ faces of these crystals 

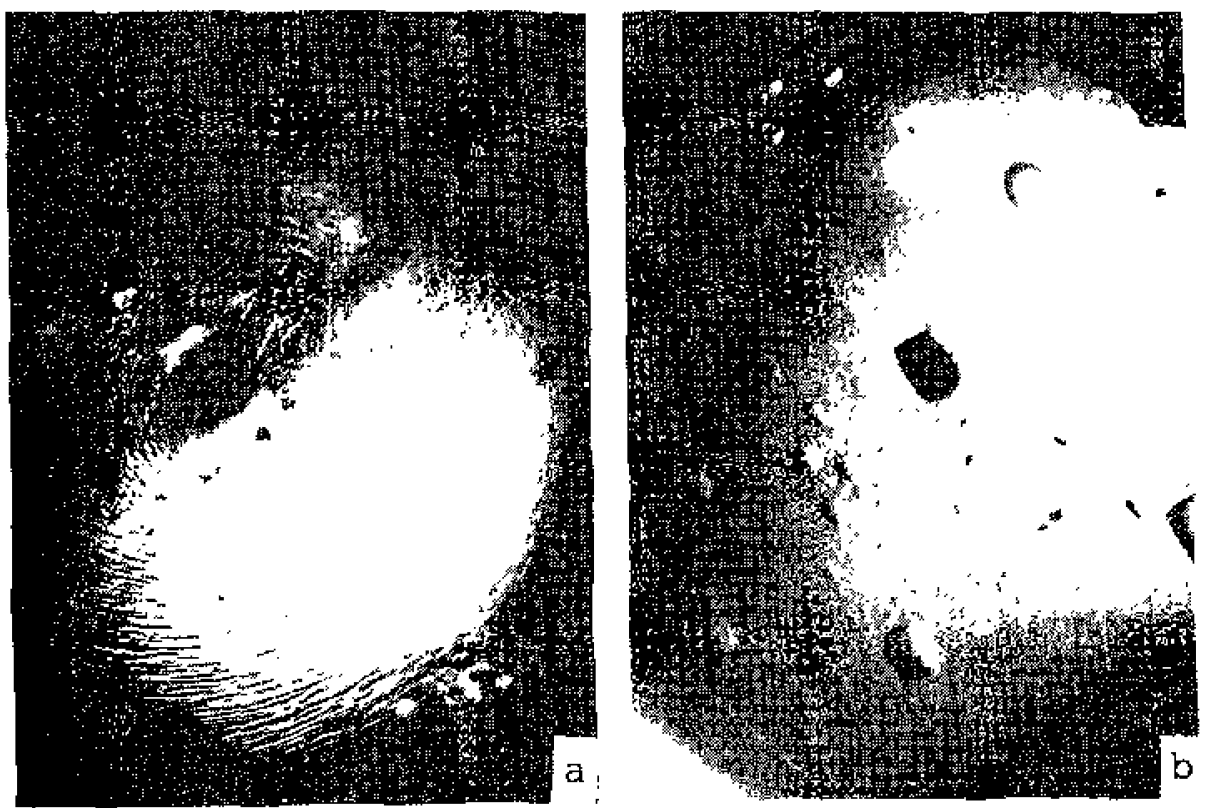

Figure 8. ar Growth billock on 4011$)$ habit face $(x 150)$. b. The etch pit produced at the centre of this growth hillock $(\times 200)$.

we have carried out etching studies on the hillock faces. Etching of these faces resulted in the formation of well-delined ctch pits on the top of the hillocks. Figures $8 \mathrm{a}$ and b show the hillock and the dislocation pit produced at the centre of the same hiljock by etching. This clearly suggests that the growth hillocks are formed at the emergence point of dislocations on these habil faces.

\subsection{X-ray topographic study}

It was mentioned earlier that on $\{011\}$ faces the hillocks of both symmetric and asymmetric shapes could be seen. In order to check if this has anylhing to do with the inclination of the dislocation line with respcct to the observation plane, we imaged the dislocations by Larg topography A transparent crystal free from all visible defects was chosen. In our invesigation (100) KTP plate containing (011) sectors was inaged using (040) rellection so that the distribution and inclination of dislocations emerging on the $\{011\}$ faces could be seen. The topograph is shown in figure 9a and the schematic diagram of the topograph in figure $9 \mathrm{~b}$. In the topograph, the lower portion of the crystal was not imaged properly because of the increase in thickness of the crystal. As can be seen from figure $9 \mathrm{~b}$ the dislocation configuration is characteristic of solution grown crystals. The dislocations are straight and mainly originate from the central nucleus though some dislocations also originate from inclusions. The topograph also reveals that a large volume of KTP crystals which are relatively defect-free can be obtained by employing the llux technique. Releming to figure $9 \mathrm{~b}$. two types of dislocations are seen to emerge from (011) face. Those marked $D_{1}$ emerge more or less normally to the growing face whereas those marked $D_{3}$ emerge at oblique angles. Also, hecause of their oblique nature, $D_{2}$ type usually emerge at the peripheral regions 


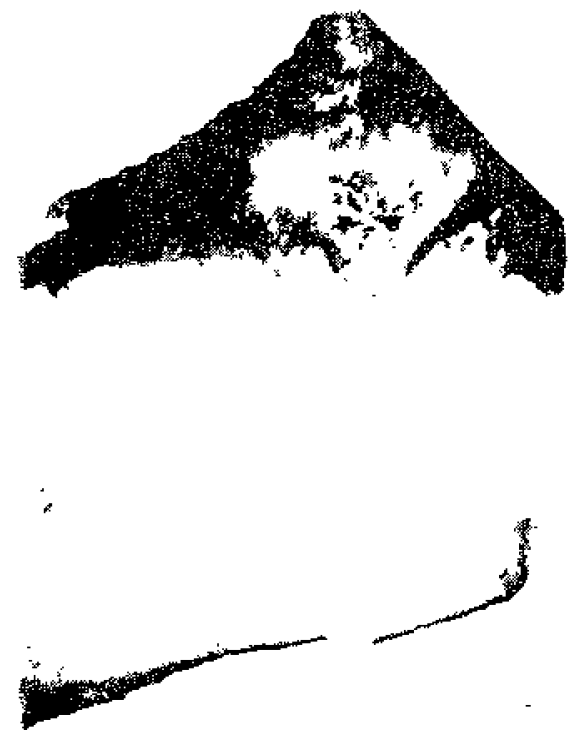

(a)

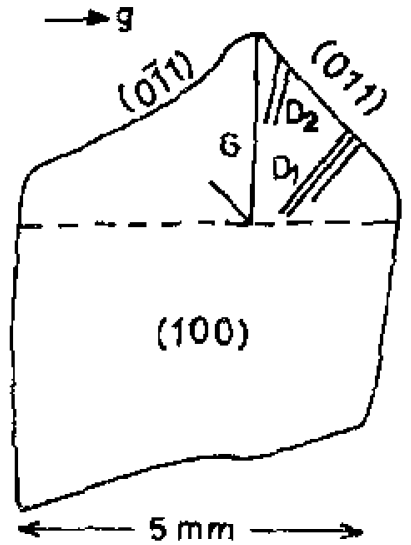

(b)

Figure 9. I. Topograph of KTP crys[a]. (040) reticction. h. Schemitic diagram of the topograph, $D_{1}, D_{2}$, dislocations; $\mathrm{G}$, growth sector boundary.

of the (011) faccs. It is likely that the $D_{2}$ dislocations give rise to asymmetric hillocks while those of $\mathrm{D}_{1}$ give symmetric hillocks. This is further confirmed by the fact that the asymmetric hillocks are always formed at the peripheral regions of $\{011\}$ babit faces as is evident from figure $3 \mathrm{~b}$.

\section{Conclusions}

The KTP crystals grown lising potassium phosphate flux are, in general, of high perfection. The flux inclusions and dendritic lealures could be minimized by optinizing the growth condition. Layer growth mechanism was observed on $\{100\}$ habit laces. Growth hillocks were observed on $\{011\}$ habit faces at the emergence points of dislocations and their shapes secm to have a correlation with the incination of the energing dislocation. Etching and preliminary $\mathrm{X}$-ray topographic studies carried out on these crystals confirm that crystals with very low dislocation density can be grown employing the flux method.

\section{Acknowledgement}

The authors thank the University Grants Comtnission, New Delhi, for financial support through the UGC COSIST programme. The work was also supported by DRDO, New Delhi through a project grant. 


\section{References}

Ballman A A, Brown H, Olson D H and Rice C E 1986 J. Cryst. Growth 75390 Jierlein J D and Vatherzecle H $1989 \mathrm{~J}$, Opt. Soc, Am. B6 622

Bolt R J, de Hias H, Sebastian M T and Klapper H 1991a J. Cryst. Growth 110587

Bolt R J, van der Mooren M and Sebastian M T 199lb J. Cryst. Growth 112773

Cai D and Yang Z 1986 J. Cryst. Growth 79974

Dhanamj $G$ and Bhat H L 1990 Mater. Lett. 10283

tliev K, Peshev P. NikoJov V and Koseya I $1990 \mathrm{~J}$. Cryst. Growth 100225

Tordjman I, Masse R and Guitel J C 1974 Zeit. Kriat. 139103

Yanoyskii V K and Voronkova V I 1986 Phys. Status Solidi 193668

Zumsteg F C, Bierlein J D and Gier T E 1976 J. Appl. Phys. 474980 